\title{
Study on Influence of Window Form on Indoor Natural Ventilation in Super High- Rise Buildings
}

\author{
Min ZHOU ${ }^{\mathrm{a}, \mathrm{b}}$, Xiaoning $\mathrm{SU}^{\mathrm{c}, 1}$ and Yuxian $\mathrm{WU}^{\mathrm{d}}$ \\ ${ }^{a}$ China Northwest Architecture Design and Research Institute Co., Ltd, Xi'an, Shaanxi, \\ China \\ ${ }^{\mathrm{b}}$ State Key Laboratory of Green Building in Western China, Xi'an University of \\ Architecture \& Technology, Xi'an, Shaanxi, China \\ ' Xi' an University of Architecture \& Technology, Xi'an, Shaanxi, China \\ ' CCDI GROUP, Shenzhen, Guangdong, China
}

\begin{abstract}
As the Chinese government is committed to reducing peak carbon dioxide emissions by 2030 and achieving carbon neutral by 2060, it is crucial to get this target by reducing energy consumption in super-high buildings. The running time of mechanical ventilation systems could be cut down by utilizing natural ventilation through windows in specific periods. In order to improve the performance of natural ventilation effectively, the study on the characteristics of window forms in super tall buildings is put forward. In this paper, the effects of different window types on natural ventilation in super high-rise buildings were investigated. Field investigation and field tests were carried out in this research. The results show that the narrow and long windows can provide a better ventilation effect. This study provides some suggestions for architects to select the window opening form in super high-rise buildings.
\end{abstract}

Keywords. Carbon dioxide emission, mechanical ventilation systems, environment protection

\section{Introduction}

Natural ventilation has been demonstrated to be an effective way for maintaining a comfortable and healthy indoor environment, as well as offering an energy-saving alternative to mechanical ventilation [1]. The effectiveness of natural ventilation on improving indoor environment and saving energy depends on the external wind conditions, building designs and internal partitions [2]. In order to optimally utilize winddriven ventilation in super-high-rise buildings, a reliable evaluation method of window forms was needed.

Direct window opening is the most common natural ventilation method for superhigh buildings at present. However, most super-high buildings with $200 \mathrm{~m}$ levels are equipped with windows on the exterior facade. Grabe et al. [3] experimentally tested hanging windows, up and down sliding windows and casement windows. When the

1 Corresponding Author, Xiaoning SU, Xi'an University of Architecture \& Technology, Xi'an, Shaanxi, China; Email: Xiaoning9617@163.com. 
ventilation rate is used as the evaluation index, it is proved that the casement window has the best ventilation performance. This investigation shows that the impact of different window types on air change rate varies dramatically according to the wind direction [4, 5]. The results show that the upper hanging window has the highest ventilation rate, which is determined by the average wind speed of all wind directions. Pengnie [6] compared different situations of window opening and found that the position of window opening had an impact on natural ventilation. Helenice [7] concluded that the distribution of air flow in indoor environment depends on the dimension of windows. Wang [8-10] analyzed several typical building windows. Although the window area is almost the same, the different window forms lead to different ventilation rates in different buildings. Liu [11] quantified the hourly ventilation rate under different window types by establishing a mathematical model. The ventilation performance of windows with air changes rate $(\mathrm{ACH})$ is evaluated. Based on the analysis of the characteristics of the windows, this paper formulates the window opening strategy to improve the utilization rate of natural ventilation through windows and reduce energy consumption in super high-rise buildings.

\section{Test Methods and Equipment}

To accurately demonstrate the status of natural ventilation of super high-rise buildings. Seven representative cities were selected from the five climate zones as follows: Shanghai, Tianjin, Shenyang, Nanchang, Shenzhen, Xi'an, and Chongqing. A series of surveys were conducted on 264 super-high buildings over 200 meters in these seven cities.

A total of 264 super high-rise buildings were surveyed for the study, of which 198 had opening fans. The opening mode of external and upper hanging windows are adopted in the glass curtain walls of 182 super high-rise buildings. For the left buildings, the external horizontal sliding windows are used in eight of them, and the other eight buildings are equipped with internal horizontal opening windows.

\subsection{Test Objects}

At present, a facade of three sections of hanging windows and a central core tube layout is adopted by many super high-rise buildings in Xi'an. In order to be more representative and universal, four super high-rise buildings with similar layouts were selected as the test objects in Xi'an. The main building of Building A has 51 floors above ground and 3 floors below ground. The total height of building A is $190 \mathrm{~m}$ high. Besides, the height of the main building B, C and D all exceeds $100 \mathrm{~m}$. The main building $\mathrm{B}$ has 35 floors above ground and 2 floors below ground. The main building $\mathrm{C}$ has 36 floors above ground and 2 floors below ground; the main building D has 35 floors above ground and 2 floors underground.

\subsection{Test Instrument}

The test instrument and their parameters are as table 1. 
Table 1. The test instrument parameters.

\begin{tabular}{lllll}
\hline Parameters & Name & Range & Precision & Resolution ratio \\
\hline $\begin{array}{l}\text { Pressure difference } \\
\text { Outdoor wind speed }\end{array}$ & Testo512 & $0 \sim \pm 200 \mathrm{~Pa}$ & $5 \%$ & $0.1 \mathrm{~Pa}$ \\
Window wind speed 410-2 wheel anemometer & $0.4 \sim 20 \mathrm{~m} / \mathrm{s}$ & $\pm(0.3 \mathrm{~m} / \mathrm{s}+2 \%)$ & - \\
$\begin{array}{l}\text { DT3880 thermo-sensitive } \\
\text { anemometer }\end{array}$ & $0.1 \sim 25 \mathrm{~m} / \mathrm{s}$ & $5 \% \pm 0.03 \mathrm{~m} / \mathrm{s}$ & $0.01 \mathrm{~m} / \mathrm{s}$ \\
Indoor wind speed & $\begin{array}{l}\text { DT380 thermo-sensitive } \\
\text { anemometer }\end{array}$ & $0.1 \sim 25 \mathrm{~m} / \mathrm{s}$ & $5 \% \pm 0.03 \mathrm{~m} / \mathrm{s}$ & $0.01 \mathrm{~m} / \mathrm{s}$ \\
\hline
\end{tabular}

\subsection{Test Methods}

\subsubsection{Thermal Pressure Test}

The measured floors of thermal pressure were shown in table 2 . The pitot tube was placed inside and outside the measured area to achieve the pressure difference between inside and outside the elevator shaft. When the internal pressure is larger than the external pressure, the recorded measurement value is positive and vice versa. The data is averaged in the 30 s of the tests.

Table 2. Measured floor of thermal pressure.

\begin{tabular}{ll}
\hline $\mathrm{z}$ & Measured floor \\
\hline $\mathrm{A}$ & $\mathrm{B} 2 \mathrm{~F}, \mathrm{~B} 1 \mathrm{~F}, 1 \mathrm{~F}, 6 \mathrm{~F}, 12 \mathrm{~F}, 14 \mathrm{~F}, 18 \mathrm{~F}, 24 \mathrm{~F}, 30 \mathrm{~F}, 36 \mathrm{~F}, 42 \mathrm{~F}, 48 \mathrm{~F}, 51 \mathrm{~F}$ \\
\hline
\end{tabular}

\subsubsection{Indoor Wind Speed Test}

The five-point method is adopted in this test. The test area is less than $60 \mathrm{~m}^{2}$. In order to make the test data more accurate, the measurement points are chosen appropriately. The laser rangefinder is used to determine the horizontal position of the measuring point and ensure the horizontal distance from the wall larger than $0.5 \mathrm{~m}$. Labeling paper is used to mark on the ground. The thermal anemometer is placed at the height of $1.2 \mathrm{~m}$ above the ground, and the average data of the monitoring point within 3 minutes is taken. The test floor summary is as table 3 .

Table 3. Test floor.

\begin{tabular}{ll}
\hline Buildings & Test location \\
\hline Building A & $32 \mathrm{~F}$ \\
Building B & $30 \mathrm{~F}$ \\
Building C & $27 \mathrm{~F}$ \\
Building D & $28 \mathrm{~F}$ \\
\hline
\end{tabular}

\subsection{The Error Analysis}

(1) Instrument error: the runner wind speed and thermal wind speed models are not unified, and the sensitivity is not consistent.

(2) Environmental error: during the test of thermal pressure, the fire elevator shaft of the tested core barrel was in use. Although the test was conducted in a static state, the floor stopped by the elevator was not consistent. In addition, the opening and closing of the elevator door would also affect the test data. During the thermal-pressing test, the front door of individual floors was not closed because of the user's needs. As the tests were not conducted on the same day, there was no guarantee that the outdoor parameters 
during the tests were consistent.

(3) Human error: since the measurement is instantaneous, the tester converts the instantaneous value within a period to the average value, and there is an error.

\section{Results and Discussion}

\subsection{The Thermal Pressure Difference for Different Building Floors}

The test result between the thermal pressure difference and building floor was shown in figure 1. The thermal pressure difference of B1, B2, 1st and 48th floor is more extensive than other floors because the door of the first floor and the basement cannot be closed, and some of the interior areas on the top floor have direct contact with the outside world. The front doors of other floors are closed. The thermal pressure difference between inside and outside the shaft is quite tiny, which alleviates the chimney effects in the shaft and effectively inhibits the thermal pressure action. From the numerical distribution of thermal pressure, it shows that the neutral plane of the building is near the 30th floor.

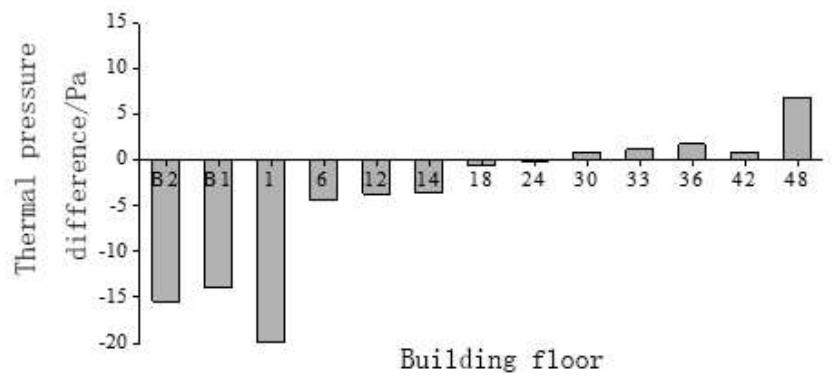

Figure 1. The thermal pressure difference for different building floors.

\subsection{Wind Speed Ratio vs. Window State}

The location of the wind speed test point is shown in figure 2. Point $\mathrm{P}_{2}$ is chosen as the test reference point. The ratio of the wind speed at a point to that of $\mathrm{P}_{2}$ is called wind speed ratio.

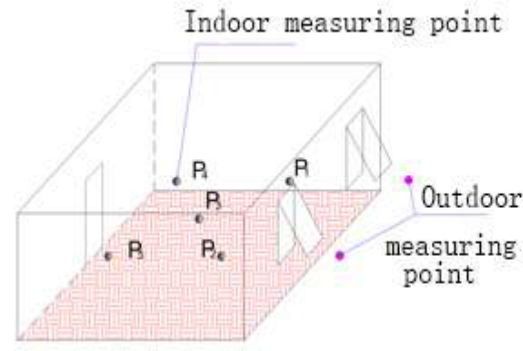

(a)

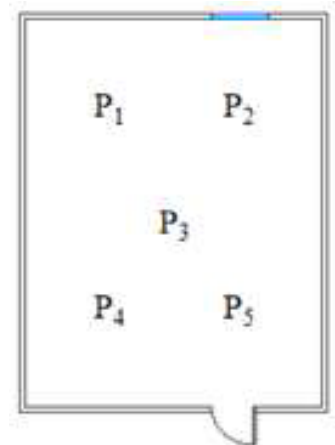

(b)

Figure 2. Location of wind speed test point. 
As shown in figures 3 and 4, the wind speed ratio with the window fully opening is more significant than that with the window half-opening. In the 1st working condition, the window has the largest opening area of $1.5 \mathrm{~m}^{2}$, which is narrow and long. In the 2nd working condition, the opening area is $0.9 \mathrm{~m}^{2}$, which the opening fan is narrow and long. The opening area of the $3 \mathrm{rd}$ working condition is $0.48 \mathrm{~m}^{2}$, which is narrow and long. The opening area of the 4th working condition is $0.96 \mathrm{~m}^{2}$, which is flat. For the upper hanging window, the wind speed ratio at each measuring point in the 1st working condition is the largest, followed by the 2 nd and 4 th working conditions. The wind speed ratio in the $3 \mathrm{rd}$ working condition is the smallest, no matter in the fully opening or partially opening state. The larger the window area, the greater the ratio of indoor wind speed, the more uniform the distribution of indoor wind speed, the ideal indoor ventilation effect.

When the areas are almost equal, the ratio of wind speed at each measuring point in case 2 is between 0.58 and 1.01; while the ratio of wind speed in case 4 is between 0.49 and 1.03, which indicates that the indoor wind speed distribution uniformity of the narrow and long open fan is better than that of the flat open fan as the area of the open fan is constant.

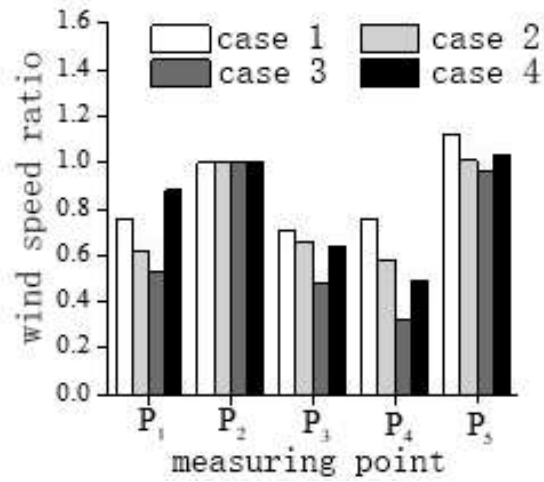

Figure 3. Wind speed ratio with window fully opening.

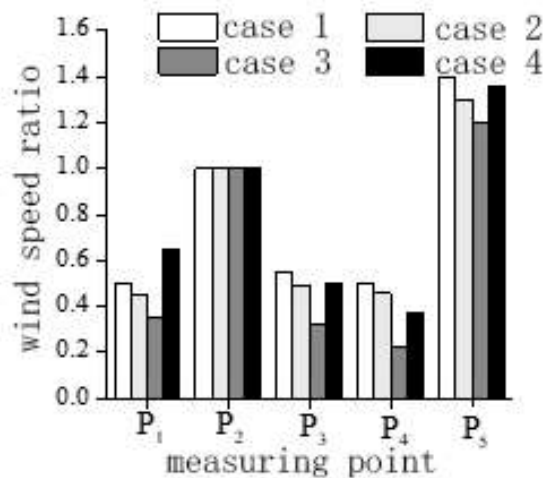

Figure 4. Wind speed ratio with window halfopening.

\section{Conclusions}

In this study, combined with the investigation on the status of the window opening in super high-rise buildings, the field measurement of the window opening ventilation in super high-rise buildings was carried out. Through the analysis of survey data and measured data, the following conclusions are drawn:

(1) Investigation data on the status of the window opening in seven cities show that the proportion of buildings with opening fans between $200 \mathrm{~m}$ and $400 \mathrm{~m}$ in height is about $77.3 \%$, of which buildings with external opening and upper hanging windows account for about $91.9 \%$ of the number of buildings with opening fans, far exceeding those with internal flat opening and pushing window forms.

(2) Influence of window opening fan shape on indoor ventilation. The narrow and long shape can provide a better ventilation effect. Therefore, the proportion of the opening fan should be set reasonably in actual projects, and the height of the opening fan should be larger than the width. 


\section{Acknowledgements}

The project was supported by The Open Project of State Key Laboratory of Green Building in Western China (LSKF201902).

\section{References}

[1] Mochida A, Yoshino H, Takeda T, Kakegawa T and Miyauchi S 2005 Methods for controlling airflow in and around a building under cross ventilation to improve indoor thermal comfort Wind Engineering, and Industrial Aerodynamics 93 437-449.

[2] Etheridge D and Sandberg M 1996 Building Ventilation: Theory and Measurement (Chichester, England: John Wiley and Sons).

[3] Grabe J V, Svoboda P and Baeumler A 2014 Window ventilation efficiency in the case of buoyancy ventilation Energy and Buildings 72 203-211.

[4] Wang H J 2005 Development of simple semi-empirical models for calculating airflow through hopper, awning, and casement windows for single-sided natural ventilation Energy and Buildings 96 373-384.

[5] Wang H J 2015 Modeling of the impact of different window types on single-sided natural ventilation Energy Procedia 78 1549-1555.

[6] Peng N 2015 Numerical study on the effect of natural ventilation and optimal orientation of residential buildings in Changsha, China Procedia Engineering 121 1230-1237.

[7] Sacht H 2016 Study of natural ventilation in wind tunnels and influence of the position of ventilation modules and types of grids on a modular façade system Energy Procedia 96 953-964.

[8] Wang J 2017 Assessment of single-sided natural ventilation driven by buoyancy forces through variable window configurations Energy and Buildings 139 762-779.

[9] Wang J, Zhang T, Wang S, et al. 2017 Gaseous pollutant transmission through windows between vertical floors in a multistory building with natural ventilation Energy and Buildings 2017 S0378778817318303.

[10] Wang J, Zhang T, Wang S, et al. 2018 Numerical investigation of single-sided natural ventilation driven by buoyancy and wind through variable window configurations Energy and Buildings 168 (Jun.) 147164.

[11] Liu T and Lee W L 2019 Using response surface regression method to evaluate the influence of window types on ventilation performance of Hong Kong residential buildings Building and Environment 154167 181. 